\title{
Love for Brothers and Friends Featured as Behavioral, Emotional, and Cognitional to Confer on Religion and Ethics
}

\author{
Mihyang Ju',2, Yi Li1',3, Yang Lee ${ }^{1,4}$ \\ ${ }^{1}$ Center of Gih Study, Jinju, South Korea \\ ${ }^{2}$ Department of Education, Korea National Open University, Seoul, South Korea \\ ${ }^{3}$ Department of Ethics Education, Gyeongsang National University, Jinju, South Korea \\ ${ }^{4}$ Zhengzhou Normal University, Zhengzhou, China \\ Email: moran2017@hanmail.net, creasy66795@gmail.com, yangleepsy@gmail.com
}

How to cite this paper: Ju, M., Li, Y., \& Lee, Y. (2019). Love for Brothers and Friends Featured as Behavioral, Emotional, and Cognitional to Confer on Religion and Ethics. Psychology, 10, 1485-1492. https://doi.org/10.4236/psych.2019.1011097

Received: July 17, 2019

Accepted: August 20, 2019

Published: August 23, 2019

Copyright ( 2019 by author(s) and Scientific Research Publishing Inc. This work is licensed under the Creative Commons Attribution International License (CC BY 4.0).

http://creativecommons.org/licenses/by/4.0/

\begin{abstract}
Love is thought as a purpose, conferring on ethics and religions and as means used to varieties of social relations. This study's tool of the questionnaire was designed to ask people how loves of brothers (or sisters), and friends both of which are critical for religion and ethics are distributed on the dimensions as behavioral, emotional, and cognitional, comparing the features of other loves. This study's results of rating response on 7 -scale were $F$ tested to show that the love for brothers is more emotional, less cognitional, and less behavioral than the profiles of love for friends, and furthermore that love for brothers is similar to love for parents, and love for friends to love for partner. This study's implication is commented as that the love features for bothers, and for friends could be attended by moral and religious concerns for human happiness since they have been misunderstood by some prejudices.
\end{abstract}

\section{Keywords}

Love for Brothers, Love of Friends, Behavior, Emotion, Cognition

\section{Problem and Purpose}

Love is regarded as a purpose of individual life and socialization, conferring on ethics as hedonism and utilitarianism, and religion as Christian or others. Christian's solution for human troubles is abstracted as love (Kugel, 1997). Other religions also are regressed to the principle of love as Buddhist's mercy (慈悲) (Harvey, 2013) and Confucius benevolence (仁) (Yao, 2000) insomuch as they are leveled as the high order of loves. The Unitarianism supported by Jeremy 
Bentham (1748-1832) and John Stuart Mill (1806-1873), following to the Hedonism proposed by Epicurus (341-270 BC) has a principle as the minimum of unhappiness and the maximum of happiness (Feldman, 1977), which are varied on loves practiced in human relationship. Thus, it is commented that religion and ethics could not be constituted unless love is conceptualized.

The Loves which are regarded in religions and ethics are related between self and others. The loves for other people are variously named as one for brothers (or sisters), friends, neighbors, and unspecified people in society, nation, and world. They are varied on the intimacy of a relationship, exampling that love for brothers (it includes love for sisters and abbreviated as B love) is more intimate, compared to others. So the calling others as "Brother" is recommended and instigated in Church, inflaming the sublime love which is aimed by the religious doctrine shown in Bible (St. Augustine, 2013; Boethius, 2012). The less intimacy is followed by love for friends (abbreviated as F love) which is regarded as a model of love for the purpose of wellbeing, so calling others as "Friend" in Confucius (Wilson, 1996; Yao, 2000), used to build a system of collaboration in society. However, it is concerned that B and F love would be different because the former is formed of blood in the family to customize to home, and the latter is adapted to the affiliated society and purported to the living business if supposed. So, how the two loves are compared requires analysis of psychological processes in references to religious and ethical relationship.

Love is thought as a tool which is used to varieties of social relations, built in all spectrums of mental processes. Love is a source of human relations insomuch as saying that society is sustained and supported by individuals who are connected by love to overcome the antisocial problems. So, the love is a variable of social attitude which consists of multi aspects as behavioral, emotional, and cognitional (Breckler, 1984; Rosenberg \& Hovland, 1960). In the rationale of the social attitude, Lee and others (Lee, Jeong, \& Lee, 2017; Lee, Kim, \& Lee, 2019; Hong, Lee, \& Lee. 2019; Sohn, Lee, \& Lee, 2018) invented a paradigm of the inner processes presupposing that the multi aspects are not divided, but hierarchically interacted as the causal level as cognitional, the motivational level as emotional, and the expressed level as behavioral (so called as BEC hierarchy). In perspective of the BEC, an expressed behavior is definitely a result of emotional motivation which is supported deeply by a causal cognition, exampled in Lee and others study, analyzing human activities as loves, labors, and social efforts. A research reported by Ju, Lee, \& Lee (2018) concluded that the love of between man and woman (abbreviated as M-W love), love between parent and child (abbreviated as P-C love), and love between God and human (abbreviated as G-H love) are differentiated in scales of the BEC dimensions. In review, P-C love compared to the other two loves is highest in emotion and moderate in cognition, but lowest in behavior, showing the love behavior does not express so much high as in emotion and cognition. G-H love is similar compared to P-C love, though a little lower in emotion and in cognition, but a little higher in behavior. However, M-W love is highest in behavior straightly expressed as high as in 
emotion and in cognition even though both of which are moderate. Following to the above analysis, the $\mathrm{B}$ and $\mathrm{F}$ love which this study concerns, require to be analyzed on BEC dimensions to understand the religious and social processes, exampled as calling "Brother" and "Friend" for other people.

Regarding BEC approaches, this study attempts to analyze B and F love which are critical for social relationship in religion and ethics. It is hypothesized that the two types of love would be featured on BEC dimensions. And the following hypothesis proposes that the two loves could be compared to M-W, P-C, and $\mathrm{G}-\mathrm{H}$ love since analyzed on BEC. With the hypotheses, this study was designed to analyze responses on a questionnaire, described in "Method" followed. If the hypotheses are confirmed, it is useful for the theorization of loves and a practical application to religion, ethics and educational problems.

\section{Method}

\subsection{Participant}

75 people were sampled at two universities (Gyeongsang National University, Korea National Open University). 73 people agreed to respond to a questionnaire constructed for this research. All participants are covered by Gyeonsang National University IRB's Codes for Human Subject Protection to assure their freedom and right in this study.

\subsection{Experimental Material}

A questionnaire was constructed for this study. The questionnaire was partitioned into introduction, items of participant's social statuses, and questions of love attributes. The introduction was written to make participant understand purposes of this study, written as "This study attempts to analyze features of love for brothers (sisters) and friends. It is stated that they are featured by three dimensions as behavioral, emotional, and cognitional". To make sure participant's freedom and right, the notices were added as "You are free at any way of whether you respond to items not wholly or partially, and your name is not permitted written. Your responses which are converted to some statistical forms are used only for the research purposes. Your freedom and right are covered by the IRB's codes of the human subject protection."

The items of social status were asked for genitals (male or female), ages (20 years, 30 years or above), jobs and religions (Buddhist, Christian, or Atheist). And more whether having brothers and sisters or not, and having many friends or little, were included.

The main question consists of attributes of $\mathrm{B}$ and $\mathrm{F}$ love which distribute on the three dimensions of BEC. Each dimension includes two identical items. For example, an item for the behavior of $F$ love, "How much are you taking out-door leisure with your friend?" and "How much are you taking skin-ship with your friend?" and for the behavior of B love the same two questions substituting "your brother and sister". For the emotion of F and B love, the two aspects, "feel favor 
for" and "feel trust", and for cognition, "understand" and "plan your future with" were extended. And for each of B and F love, similarity to M-W, P-C, and G-H love was asked for example, B love's similarity to P-C love "How much similar is your love for brothers to your love for parents?" Thus, the total items amount to $18=12(2 \times 3 \times 2)+6(2 \times 3)$. Each question as "How much---" was rated by participants in 7 scale of from very low 1 to very high 7 .

\subsection{Procedural}

Two experimenters visited 2 universities in Jinju, South Korea for data collection. When the experimenters met groups of the participant or personal participants, they asked them to respond to the experimental questionnaire. While the experiments got participants' consent for responses, they gave them the whole questionnaire, let them read the introduction, and exchange questions and answers for some problems misunderstood, and then had them to go on responding to the items of the questionnaire. Until every participant finished responding, the experiment kept aside to guide the experiment.

\section{Result and Discussion}

Among the 75 participants, two people did not want to finish their responses. So the 73 participants' responses to the questionnaire were input to statistical processes of descriptive statistic, and analysis of variance. The statistical analysis was processed by SPSS (v. 21.0).

\subsection{The Profiles of B Love and F Love on BEC Dimensions}

For this study purposes, the profiles of B and $\mathrm{F}$ love on BEC dimensions and $F$ tests are required for comparison. Figure 1 and Table 1 showed the profiles were differentiated. The main effect of both love types as $B$ and $F$ love and the activity dimensions as BEC were significant statistically as for the love types, $F=$ 13.006, $d f=1 / 72, M S e=1.917, p=0.001$, and for the dimensions, $F=135.076$, $d f=2 / 144, M S e=0.817, p=0.000$. However, it is not concerned because the interaction of love-types and activity dimensions was significant statistically as $F=$ 65.315, $d f=2 / 144, M S e=0.440, p=0.000$. Looking into the profiles, the two love types were differentiated. The love profiles showed commonly the highest emotional aspects, the middle cognitional, and the lowest behavioral, which suggests the behavioral expression of love is inhibited. Elaborating closely to differentiation of profiles shown, the relatively straight behavioral expression of $\mathrm{F}$ love even with the moderate emotional and cognitional level shown statistically as for behavior and emotion, $t=-6.001, d f=72, p=0.000$ and for emotion and cognition, $t=-0.082, d f=72, p=0.934$, was contrasted to that more behavioral inhibition of B love even with the high emotional level shown statistically as for behavior and emotion, $t=-15.866, d f=72, p=0.000$ and for emotion and cognition, $t=7.438, d f=72, p=0.000$. So the difference between behavior and emotion is higher in B love (2.56) than in F love (0.78). 


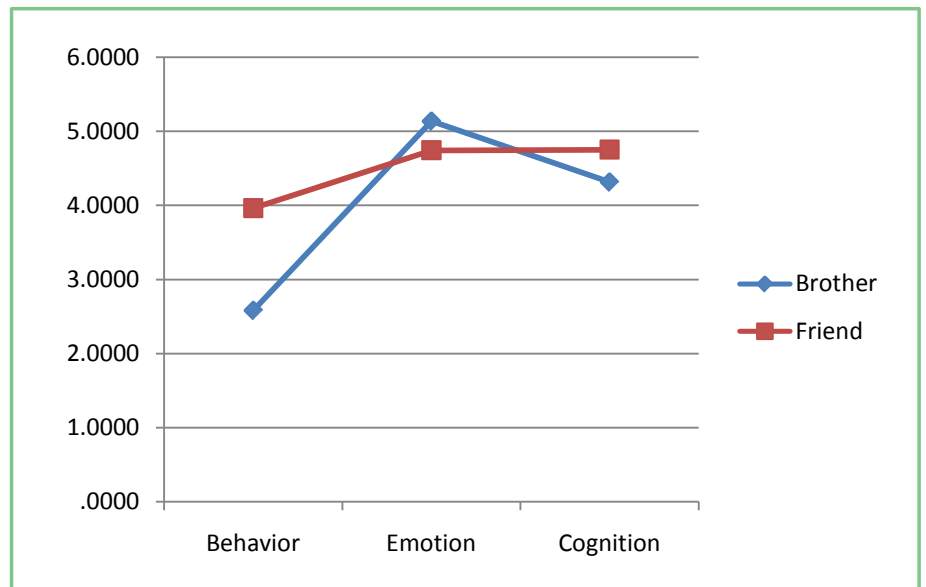

Figure 1. Profiles for B L and F L on BEC.

Table 1. Mean and $S D$ of B love and F love on BEC.

\begin{tabular}{ccccc}
\hline & \multicolumn{2}{c}{ Brother } & \multicolumn{2}{c}{ Friend } \\
\cline { 2 - 5 } & $M$ & $S D$ & $M$ & $S D$ \\
\hline Behavior & 2.58 & 1.33 & 3.97 & 1.27 \\
Emotion & 5.14 & 1.37 & 4.75 & 1.02 \\
Cognition & 4.32 & 1.12 & 4.75 & 1.10
\end{tabular}

The profiles of B and $\mathrm{F}$ love were not different in participant genitals (Male sample size, 28; Female, 45), and age stages (20 - 39 years sample size, 43; the above, 30). Moreover, B love profile was not different in whether having brothers and sisters or not. Also, F love profile was not different in whether having many friends or little. These non-significances suggested that both B and F love were relatively constant across the socio classes of between-subject variables.

\subsection{B Love and F Love Compared to Love for God, Parent, and Partner}

At the above, the love for brothers and friends are differentiated on BEC dimensions. On the same dimensions, loves for God, parent, and partner were analyzed by factors so suggesting that the latter three types of love would be fundamental to compare other loves (Ju, Lee, \& Lee, 2018). This study has 3 three items as the love of God, parents, and partners for each of $\mathrm{B}$ and $\mathrm{F}$ love divisions as introduced in the above "Method". The profiles of B and F L on the fundamental types of love are shown in Table 2 and Figure 2.

The main effect of both love types as B and F love and the fundamental love types for god, parent, and partner were significant statistically as for the love types, $F=5.880, d f=1 / 72, M S e=2.243, p=0.018$, and for the fundamental love types, $F=17.427, d f=2 / 144, M S e=1.098, p=0.000$. However, it is not concerned because the interaction of $\mathrm{B}$ and $\mathrm{F}$ love, and the fundamental love types was significant statistically as $F=40.086, d f=2 / 144, M S e=0.733, p=0.000$. 


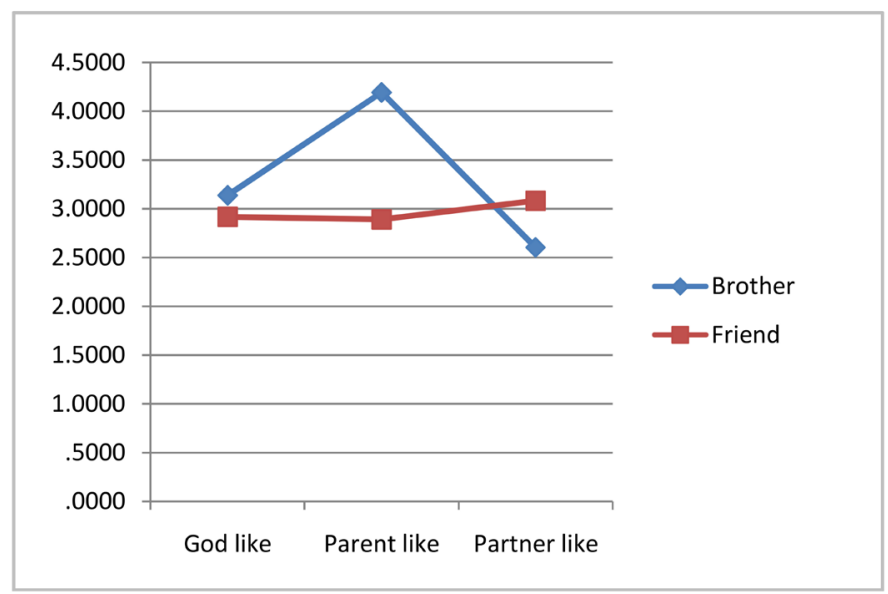

Figure 2. Similarity profiles of B love and F love to Love for god, parent, and partner.

Table 2. Similarity Mean and $S D$ of B L and F L to Love for god, parent, and partner.

\begin{tabular}{ccccc}
\hline & \multicolumn{3}{c}{ Brother } & \multicolumn{2}{c}{ Friend } \\
\cline { 2 - 5 } & $M$ & $S D$ & $M$ & $S D$ \\
\hline God-like & 3.14 & 1.69 & 2.91 & 1.42 \\
Parent-like & 4.19 & 1.64 & 2.90 & 1.35 \\
Partner-like & 2.60 & 1.63 & 3.08 & 1.60 \\
\hline
\end{tabular}

Looking into the profiles, the B and $\mathrm{F}$ love were differentiated on the three fundamental types of love. The love profiles showed that B love is highly similar to love for parent described statistically as for parent-like and god-like, $t=5.641, d f$ $=72, p=0.000$ and for parent-like and partner-like, $t=8.033, d f=72, p=0.000$. And $\mathrm{F}$ love is synonymous to love for partners in inspecting the graphic pattern related.

\section{Conclusion and Suggestion}

This study analyzed the two types of love for brother or sister (B love), and friend (F love) on the three dimensions of activities as behavioral (B), emotional (E), and cognitional (C). The profiles of $\mathrm{B}$ and $\mathrm{F}$ love on BEC dimensions are differentiated by the support of interaction between the love types and the activity dimensions which were analyzed by $F$ test. Summarizing the profiles, the B love is reluctant to express the behavior of love as much as the exited emotion which is higher than that of $\mathrm{F}$ love. In contrast, the $\mathrm{F}$ love is straight to express the behavior of love as much as the exited emotion which is even lower than that of the B love.

For some facts interested, each of the love types was not differently influenced by genital identities and age stages. More attended, the F love was not different in whether having brother or not and the $\mathrm{F}$ love was not different in whether friends are many or little. The indifferences in the personal and social variables 
suggest that the types of love are general, sharing commonality that sustaining family and society is most moral.

Since the profiles of B and F love were analyzed on BEC dimensions, they are compared to love for God, parents and partners, which was analyzed on the same BEC applied by Ju, Lee, \& Lee (2018). In comparison, this study's love for brothers is similar to love for parents analyzed by the previous study in the pattern showing that the behavior is inhibited, not expressed as much as the emotion is exited. Also this study's love for friends is similar to love for partner analyzed by the previous study in the pattern showing that the behavior is straight expressed as much as the emotion and the cognition, both of which are not even highly activated. In these points, it is evaluated that the BEC paradigm can be applied to as a common analysis to compare varieties of activities and hierarchy of consciousness as love (Ju, Lee, \& Lee, 2018), labor (Lee, Jeong, \& Lee, 2017; Lee, Kim, \& Lee, 2019), social effort (Sohn, Lee, \& Lee, 2018), kinds of soul (Hong, Lee, \& Lee, 2019), and kinds of religion (Cho \& Lee, 2017).

More suggested, a question is raised now whether the calling others as "Brother" in churches and as "Friend" in societies of commonality is reasonable. In facts, the results of this study abstract that love for brother is substituted to love for parents, and love for friends is matched to love for partners. Considering the trend, calling others "Brother" and "Friend" is commented as somewhat odd. It could be analyzed in comparison of the Eastern and Western world whether the nuances of the calling are culturally different. Though this study contributes much, it needs somewhat to advance for the next projects. This study tested within-subjects variables as the two love types and the three activity dimensions of two isomorphic questions with a large sample size of 73, amounting to the significant observations enumerated as 2 types of love $\times 3$ dimensions $\times 2$ identity items of each cell, so to sustain little limitation of generalization. However the significance or non-significance of between-subject variables to which were found in this study needs randomized samples in the next designs to test the generalizations. Advanced further, what is required for the next projects, studies would challenge to develop scales of love. This study has just differentiated the types of love profiled by BEC dimensions. To test varieties of love, diagnosing some personality types, the study should attempt a standard scale.

\section{Acknowledgements}

This research is supported by Zhengzhou Normal University. The first author, Mihyang Ju proposed the problems of this study, designed the questionnaire, and collected experimental data with the help of a co-experimenter, Gwonheui Lee who is working at Center of Gih Study. The second author Yi Li advised to interpret data, and incorporate theories of ethics, and polished the description. The correspondent author, Yang Lee supervised constructing questionnaire and interpreting data, completed theories related to philosophy and psychology, and edited this draft. 


\section{Conflicts of Interest}

The authors declare no conflicts of interest regarding the publication of this paper.

\section{References}

Boethius (2012). The Consolation of Philosophy: With an Introduction and Contemporary Criticism: Ignatius Critical Editions. New York, NY: Ignatius Press.

Breckler, S. J. (1984). Empirical Validation of Affect, Behavior, and Cognition as Distinct Components of Attitude. Journal of Personality and Social Psychology, 47, 1191-1205. https://doi.org/10.1037//0022-3514.47.6.1191

Cho, C., \& Lee, Y. (2017). The Three Dimensions of Belief Differentiating Religions. Humanities \& Social Sciences, 5, 79-83. https://doi.org/10.11648/j.hss.20170502.15

Feldman, F. (1977). Unitarianism Hedonism and Desert Essays in Moral Philosophy. Cambridge, UK: Cambridge University Press.

Harvey, P. (2013). An Introduction to Buddhism: Teachings, History and Practices. Cambridge, UK: Cambridge University Press. https://doi.org/10.1017/CBO9781139050531

Hong, B., Lee, S., \& Lee, Y. (2019). Words Related with Souls in Eastern and Western Systems. Journal of Philosophy and Ethics, 1, 20-29.

Ju, M., Lee, H., \& Lee, Y. (2018). Man-Woman, Parent-Child, and God-Human Love Featured on Behavioral, Emotional, and Cognitional Dimension. Psychology and Behavioral Sciences, 7, 14-18.

Kugel, J. L. (1997). The Bible as It Was. Cambridge, MA: Harvard University Press.

Lee, S., Jeong, J., \& Lee, Y. (2017). Three Dimensions of Labor: Cognitive Labor Differentiated from Emotional and Physical Labor. Journal of Human Resource Management, 5, 57-62. https://doi.org/10.11648/j.jhrm.20170504.11

Lee, S., Kim, S., \& Lee, Y. (2019). The Economic Purposes Related to the Labor Types. Archives of Business Research, 7, 242-250.

Lee, Y., Shaw, R. E., \& Jin, Z. (2017). Gih(Qi): Beyond Affordance. Frontiers in Psychology, 8, 556. https://doi.org/10.3389/fpsyg.2017.00556

Rosenberg, M. J., \& Hovland, C. I. (1960). Cognitive, Affective, and Behavioral Components of Attitude. In M. J. Rosenberg, C. I. Hovland, W. J. McGuire, R. P. Abelson, \& J. W. Brehm (Eds.), Attitude Organization and Change: An Analysis of Consistency among Attitude Components (pp. 1-14). New Haven, CT: Yale University Press.

Sohn, D., Lee, S., \& Lee, Y. (2018). The Three Dimensions of Social Effort. Psychology and Behavioral Sciences, 7, 8-12.

St. Augustine (2013). The Confessions of St. Augustine. Charleston, SC: Nabu Press.

Wilson, T. A. (1996). The Ritual Formation of Confucian Orthodoxy and the Descendants of the Sage. The Journal of Asian Studies, 55, 559-584. https://doi.org/10.2307/2646446

Yao, X. (2000). An Introduction to Confucianism. Cambridge, UK: Cambridge University Press. https://doi.org/10.1017/CBO9780511800887 